\title{
Relationship between PPP1R15A gene polymorphism (rs611251) and Epstein-Barr virus-associated tumors
}

\author{
Y. SONG ${ }^{1}$, S. $\mathrm{LIU}^{3}$, Z. ZHAO ${ }^{1}$, Y. ZHANG ${ }^{1,2}$, Y. YANG ${ }^{1}$, B. LUO ${ }^{1+}$
}

\begin{abstract}
${ }^{1}$ Department of Medical microbiology, Qingdao University Medical College, 38 Dengzhou Road, Qingdao, 266021, P. R. China; ${ }^{2}$ Department of Clinical Laboratory, Central Hospital of Zibo, 54 Gongqingtuan Road, ZiBo, 255036, P. R. China; ${ }^{3}$ Department of Clinical Laboratory, The Affiliated Hospital of Qingdao University, 19 Jiangsu Road, Qingdao, 266003, P. R. China
\end{abstract}

Summary. - Protein phosphatase 1, regulatory subunit 15A (PPP1R15A), also known as growth arrest and DNA damage-inducible protein GADD34, plays a vital role in promoting cell death and the unfolded protein response (UPR). In order to explore whether the SNP (rs611251) of PPP1R15A gene has a role in different types of Epstein-Barr virus (EBV)-associated tumors, we detected the PPP1R15A gene rs611251 polymorphism in 195 cases of EBV positive tumors (93 lymphomas, 48 gastric carcinomas, 54 nasopharyngeal carcinomas), 208 cases of EBV-negative tumors (136 gastric carcinoma, 19 nasopharyngeal carcinomas, 53 lymphomas) and 113 peripheral blood samples from healthy individuals. Compared with normal controls, the wild type TT and allele T of rs611251 showed higher frequency in gastric carcinoma (GCs), nasopharyngeal carcinomas (NPCs) and lymphomas. However, there was no significant difference between EBV-associated gastric (EBVaGC) and EBVnGC, EBV-positive NPCs and EBV-negative NPCs, EBV-related lymphomas and EBV-negative lymphomas in rs611251 of PPP1R15A. In conclusion, the PPP1R15A rs611251 polymorphism was significantly related to three kinds of tumors. Nevertheless, EBV has no obvious effect on PPP1R15A rs611251 polymorphism of NPC, GC and lymphoma. What's more, the genotype TT and allele T could be risk factors for NPC, GC and lymphoma. Our study explores the relationship between PPP1R15A gene polymorphism (rs611251) and EBV-associated tumors for the first time. PPP1R15A gene SNP (rs611251) have association with multiple tumor types, which may provide some new clues to the detection and treatment of tumors.

Keywords: PPP1R15A; GADD34; rs611251; gene polymorphism; Epstein-Barr virus; tumor

\section{Introduction}

Epstein-Barr virus (EBV) was the first human virus to be directly implicated in carcinogenesis and is a prevalent gamma-herpes virus infecting more than $90 \%$ of the human population worldwide. Although EBV coexists with most human hosts, persists asymptomatically for life and

*Corresponding author. E-mail: qdluobing@163.com; phone: +86$532-83812423$.

Abbreviations: PPP1R15A = protein phosphatase 1, regulatory subunit 15A; GADD34 = DNA damage-inducible protein; $\mathrm{SNP}=$ single nucleotide polymorphism; $\mathrm{EBV}=$ Epstein-Barr virus; $\mathrm{EBVaGC}=\mathrm{EBV}$-associated gastric; $\mathrm{EBVnGCs}=\mathrm{EBV}$-negative gastric carcinoma; $\mathrm{GC}=$ gastric carcinoma; $\mathrm{NPC}=$ nasopharyngeal carcinomas; EBER = EBV-encoded small RNA remains latent in B cells following resolution of infection, it has the potential to be a serious opportunistic pathogen. It has been reported that in some individuals EBV leads to the development of various malignancies, especially several human lymphoid and epithelial tumors, including lymphoma, nasopharyngeal carcinoma (NPC) and gastric cancer (GC) (Thompson et al., 2004; Akiba et al., 2008). In the pattern of EBV latent infection, three integral membrane proteins (LMP1, LMP2A and LMP2B), two non-coding poly-adenylated RNAs (EBER 1 and 2) and 6 nuclear proteins (EBNAs 1, 2 3A, 3B, 3C and LP) are expressed. LMP1 is a well-known classical oncoprotein and has been proven to be associated with NPC and lymphoma pathogenesis, whereas it cannot be found in GC (Truong et al., 2009; Chang et al., 2016). EBNA3C is essential for 
proliferation of EBV-infected B-lymphocytes as an EBVencoded nuclear protein.

PPP1R15A is a member of a group of genes whose transcript levels are increased following stressful growth arrest conditions and treatment with DNA-damaging agents. This gene induces growth arrest and the expression of DNA damage-inducible protein 34 (GADD34). It has been reported that the activation of GADD34 is a downstream event in apoptotic signaling pathways and may directly contribute to the apoptotic process (Hollander et al., 2001; Liu et al., 2015). However, more recent work has demonstrated that expression of GADD34 promoted growth of lung carcinoma and revealed the exact immunological mechanisms (Liu et al., 2016). The reduction of GADD34 expression significantly suppressed tumor, resulted in decreased accumulation of myeloid-derived suppressor cells (MDSCs) and T-cells. The inhibition of GADD34 also reduced secretion of vascular epithelial growth factor $\alpha$ and transforming growth factor $\beta$ by MDSCs (Isobe et al., 2016). It has been observed that EBNA3C can interact with GADD34 to counteract the unfolded protein response, which maintains protein homeostasis by governing the processing capacity of the endoplasmic reticulum (ER) to manage ER client loads (Garrido et al., 2009; Young et al., 2016). Moreover, it has been reported that GADD34 expression enhanced colorectal cancer (CRC) tumorigenesis (Tanaka et al., 2015). The SNP (rs557806) of PPP1R15A gene may improve the identification of metastatic colorectal cancer (mCRC) patients sensitive to bevacizumab regimens and improve personalized treatment of mCRC. This SNP might be a candidate biomarker on the basis of correlations with clinicopathologic parameters and clinical responses (Roh et al., 2016).

SNPs have been the focus of much interest and debate in recent years regarding their possible role in the development of various types of cancer (Wu et al., 2013). It is widely accepted that the significant SNPs can be used as biomarkers for diagnosis and to evaluate the risk and prognosis of some diseases including cancers (Pipan et al., 2015; Xu et al., 2015; Kuang et al., 2016). However, there is little information available in literature about PPP1R15A gene polymorphism. The role of PPP1R15A in EBV-associated carcinomas including GC, NPC and lymphomas has not yet been explored. The purpose of this study was to assess the polymorphism (rs611251) of PPP1R15A in GC, NPC and lymphomas in Northern China. Furthermore, an association between the PPP1R15A gene polymorphism (rs611251) and susceptibility to Epstein-Barr virus-associated carcinomas was also explored.

\section{Materials and Methods}

Specimens. This study was approved by the Medical Ethical Committee of the Medical College, Qingdao University. All patients participating in the present study gave informed consents for the use of tissue samples for research. We collected 146 lymphoma tissues, 184 GC tissues and 73 NPC tissues from the Department of Pathology of the Affiliated Hospital of Qingdao University, which is located in Shandong Province of northern China. None of the patients received chemotherapy, radiotherapy or hormone therapy. One hundred and thirteen peripheral blood samples, which were collected from Qingdao Blood Center, were classified as a control group. The individuals in this group have no history of cancer and did not receive any medications. EBV-associated tumors were confirmed with EBV-encoded small RNA (EBER) 1 in situ hybridization, as described previously (Tokunaga et al., 1993).

DNA extraction. DNA was extracted from fresh tumor tissues and whole-blood samples using the traditional phenol-chloroform method with proteinase K digestion (Wallace, 1987). The QIAamp DNA FFPE Tissue Kit (QIAGEN GmbH, Hilden, Germany) was used to extract DNA from paraffin-embedded carcinoma tissues. The extracted DNA was stored at $-20^{\circ} \mathrm{C}$ until the experiment was carried out.

Methods of genotyping and statistical analysis. SNPs were genotyped using Sequenom Mass-ARRAY technology, and genotypic frequencies in controls were tested in accord with Hardy-Weinberg equilibrium using Fisher's exact test $\left(\chi^{2}=0.32, P>0.05\right)$. Statistical analysis was conducted using SPSS 18.0 statistical software (SPSS, Chicago, IL, USA). The Chi-square test was used to compare differences between various types of tumor cases and controls regarding genotype and allele frequencies of rs611251 in each group. The odds ratio (OR) and $95 \%$ confidence intervals (CI) were calculated with unconditional logistic regression analysis. The odds ratio (OR) and $P$ values were used to assess the correlation between genotype and the risk among different types of tumor in present research. A twosided $P$-value $<0.05$ was defined as a significant threshold.

\section{Results}

The distribution of genotype and allelic frequency of PPP1R15A (rs611251) in GC

The PPP1R15A gene SNP (rs611251) was successfully genotyped and analyzed in 184 GC specimens including 48 EBVaGCs and 136 EBVnGCs. The results showed that the frequency of genotype TT and allele T of rs611251 was significantly higher in GC cases than in controls. Furthermore, the allele $\mathrm{C}$ showed a decreased risk of GCs. The genotypes and variants of PPP1R15A gene in the GCs are listed in Table 1. To explore the relationship between EBV infection and PPP1R15A gene polymorphism (rs611251) in GC development, we analyzed differences in the PPP1R15A genotype (rs611251) distribution between EBVaGC and EBVnGC. However, there was no significant difference between them (Table 2). Compared with controls, the genotype TT and allele $\mathrm{T}$ frequency of rs611251 was significantly higher in 
Table 1. Distribution of PPP1R15A polymorphisms in GC and control

\begin{tabular}{|c|c|c|c|c|}
\hline $\begin{array}{l}\text { Genotype/allele } \\
\text { PPP1R15A(rs611251) }\end{array}$ & $\begin{array}{c}\mathrm{GC} \\
\mathrm{n}=\mathbf{1 8 4}(\%)\end{array}$ & $\begin{array}{c}\text { Control } \\
\mathrm{n}=113(\%)\end{array}$ & OR $(95 \% C I)$ & $P$ \\
\hline \multicolumn{5}{|l|}{ Genotypic frequencies } \\
\hline $\mathrm{TT}$ & $155(84.24 \%)$ & $84(74.34 \%)$ & 1.00 & \\
\hline $\mathrm{TC}$ & $27(14.67 \%)$ & $26(23.01 \%)$ & $0.56(0.31-1.03)$ & 0.059 \\
\hline $\mathrm{CC}$ & $2(1.09 \%)$ & $3(2.65 \%)$ & $0.36(0.06-2.21)$ & 0.351 \\
\hline \multicolumn{5}{|l|}{ Recessive model } \\
\hline Others & $182(98.91 \%)$ & $110(97.35 \%)$ & 1.00 & \\
\hline $\mathrm{CC}$ & $2(1.09 \%)$ & $3(2.65 \%)$ & $0.40(0.07-2.45)$ & 0.372 \\
\hline \multicolumn{5}{|l|}{ Dominant model } \\
\hline TT & $155(84.24 \%)$ & $84(74.33 \%)$ & 1.00 & \\
\hline Others & $29(15.76 \%)$ & $29(25.66 \%)$ & $0.54(0.30-0.97)$ & $0.037^{\star}$ \\
\hline \multicolumn{5}{|l|}{ Allelic frequencies } \\
\hline $\mathrm{T}$ & $332(91.46 \%)$ & $194(85.84 \%)$ & 1.00 & \\
\hline $\mathrm{C}$ & $31(8.54 \%)$ & $32(14.16 \%)$ & $0.57(0.34-0.96)$ & $0.032^{\star}$ \\
\hline
\end{tabular}

GC: gastric carcinoma; OR: odd ratio; 95\%CI: 95\% confidence interval; * : statistical significance.

Table 2. Distribution of PPP1R15A polymorphisms in EBVaGC and EBVnGC

\begin{tabular}{|c|c|c|c|c|}
\hline $\begin{array}{l}\text { Genotype/allele } \\
\text { PPP1R15A(rs611251) }\end{array}$ & $\begin{array}{c}\text { EBVaGC } \\
\mathrm{n}=\mathbf{4 8}(\%)\end{array}$ & $\begin{array}{c}\text { EBVnGC } \\
\mathrm{n}=136(\%)\end{array}$ & OR $(95 \% C I)$ & $P$ \\
\hline \multicolumn{5}{|l|}{ Genotypic frequencies } \\
\hline TT & $38(79.17 \%)$ & $117(86.03 \%)$ & 1.00 & \\
\hline $\mathrm{TC}$ & $9(18.75 \%)$ & $18(13.24 \%)$ & $0.65(0.27-1.57)$ & 0.334 \\
\hline $\mathrm{CC}$ & $1(2.08 \%)$ & $1(0.73 \%)$ & $0.33(0.02-5.32)$ & 0.436 \\
\hline \multicolumn{5}{|l|}{ Recessive model } \\
\hline Others & $47(97.92 \%)$ & $135(99.26 \%)$ & 1.00 & \\
\hline $\mathrm{CC}$ & $1(2.08 \%)$ & $1(0.74 \%)$ & $0.35(0.02-5.68)$ & 0.439 \\
\hline \multicolumn{5}{|l|}{ Dominant model } \\
\hline $\mathrm{TT}$ & $38(79.17 \%)$ & $117(86.02 \%)$ & 1.00 & \\
\hline Others & $10(20.83 \%)$ & $19(13.97 \%)$ & $0.62(0.27-1.46)$ & 0.262 \\
\hline \multicolumn{5}{|l|}{ Allelic frequencies } \\
\hline $\mathrm{T}$ & $85(88.54 \%)$ & $248(92.53 \%)$ & 1.00 & \\
\hline $\mathrm{C}$ & $11(11.46 \%)$ & $20(7.46 \%)$ & $0.62(0.29-1.35)$ & 0.229 \\
\hline
\end{tabular}

EBVaGC: EBV-associated gastric carcinoma; EBVnGC: EBV-negative gastric carcinoma; OR: odd ratio; 95\%CI: 95\% confidence interval.

EBVnGCs. Furthermore, the TC genotype and allele C showed a decreased risk of EBVnGCs. No significant difference was found between EBVaGCs and control (Table 3).

The distribution of genotype and allelic frequency of PPP1R15A (rs611251) in NPC

The PPP1R15A gene SNP (rs611251) was successfully genotyped and analyzed in 73 NPC specimens including 54 EBV-positive NPCs and 19 EBV-negative NPCs. The frequency of genotype TT and allele T was significantly higher in EBV-positive NPCs and EBV-negative NPCs than that in controls. Furthermore, the genotype TC and allele $\mathrm{C}$ showed a decreased risk for NPCs. The genotypes and variants of latent genes in the NPCs are listed in Table 4. However, no significant difference was found between EBV-positive NPCs and EBV-negative NPCs (Table 5).

The distribution of genotypic and allelic frequency of PPP1R15A (rs611251) in lymphomas

The PPP1R15A gene SNP (rs611251) was successfully genotyped and analyzed in 146 lymphoma specimens including 93 EBV-positive lymphomas and 53 EBV-negative lymphomas. The results showed that TT genotype and allele T frequency of rs611251 was significantly higher in EBV-positive lymphomas 
Table 3. Distribution of PPP1R15A polymorphisms in EBVnGC, EBVaGC and control

\begin{tabular}{|c|c|c|c|}
\hline $\begin{array}{l}\text { Genotype/allele } \\
\text { PPP1R15A(rs611251) }\end{array}$ & $\begin{array}{c}\text { EBVnGC } \\
n=136(\%)\end{array}$ & $\begin{array}{c}\text { Control } \\
\mathrm{n}=113(\%)\end{array}$ & $\begin{array}{c}\text { EBVaGC } \\
\mathrm{n}=48(\%)\end{array}$ \\
\hline \multicolumn{4}{|l|}{ Genotypic frequencies } \\
\hline TT & $117(86.03 \%)$ & $84(74.34 \%)$ & 38 (79.17\%) \\
\hline TC & $18(13.24 \%)$ & $26(23.01 \%)$ & $9(18.75 \%)$ \\
\hline OR(95\%CI) & $0.50(0.26-0.97)$ & & $0.77(0.33-1.79)$ \\
\hline$P$ & $0.0370^{*}$ & & 0.54 \\
\hline $\mathrm{CC}$ & $1(0.73 \%)$ & $3(2.65 \%)$ & $1(2.08 \%)$ \\
\hline OR(95\%CI) & $0.24(0.02-2.34)$ & & $0.74(0.07-7.32)$ \\
\hline$P$ & 0.314 & & 1.00 \\
\hline \multicolumn{4}{|l|}{ Recessive model } \\
\hline Others & 135 (99.26\%) & $110(97.35 \%)$ & 47 (97.92\%) \\
\hline $\mathrm{CC}$ & $1(0.74 \%)$ & $3(2.65 \%)$ & $1(2.08 \%)$ \\
\hline OR(95\%CI) & $0.27(0.03-2.65)$ & & $0.78(0.08-7.70)$ \\
\hline$P$ & 0.332 & & 1.00 \\
\hline \multicolumn{4}{|l|}{ Dominant model } \\
\hline TT & $117(86.02 \%)$ & $84(74.34 \%)$ & $38(79.17 \%)$ \\
\hline Others & $19(13.97 \%)$ & $29(25.66 \%)$ & $10(20.83 \%)$ \\
\hline OR(95\%CI) & $0.47(0.25-0.90)$ & & $0.76(0.34-1.72)$ \\
\hline$P$ & $0.020^{*}$ & & 0.51 \\
\hline \multicolumn{4}{|l|}{ Allelic frequencies } \\
\hline $\mathrm{T}$ & $248(92.53 \%)$ & $194(85.84 \%)$ & $85(88.54 \%)$ \\
\hline $\mathrm{C}$ & $20(7.46 \%)$ & $32(14.16 \%)$ & $11(11.46 \%)$ \\
\hline OR(95\%CI) & $0.49(0.27-0.88)$ & & $0.79(0.38-1.63)$ \\
\hline$P$ & $0.016^{*}$ & & 0.52 \\
\hline
\end{tabular}

EBVnGC: EBV-negative gastric carcinoma; EBVaGC: EBV-associated gastric carcinoma OR: odd ratio; $95 \%$ CI: $95 \%$ confidence interval; ${ }^{*}$ : statistical significance.

Table 4. Distribution of PPP1R15A polymorphisms in NPC and control

\begin{tabular}{|c|c|c|c|}
\hline $\begin{array}{l}\text { Genotype/allele } \\
\text { PPP1R15A(rs611251) }\end{array}$ & $\begin{array}{c}\text { NPC }(+) \\
\mathrm{n}=54(\%)\end{array}$ & $\begin{array}{c}\text { Control } \\
n=113(\%)\end{array}$ & $\begin{array}{c}\text { NPC(-) } \\
n=19(\%)\end{array}$ \\
\hline \multicolumn{4}{|l|}{ Genotypic frequencies } \\
\hline TT & $48(88.89 \%)$ & $84(74.34 \%)$ & $19(100 \%)$ \\
\hline TC & $5(9.26 \%)$ & $26(23.01 \%)$ & $0(0 \%)$ \\
\hline $\mathrm{OR}(95 \% \mathrm{CI})$ & $0.34(0.12-0.93)$ & & $0.76(0.69-0.85)$ \\
\hline$P$ & $0.030^{*}$ & & $0.013^{\star}$ \\
\hline $\mathrm{CC}$ & $1(1.85 \%)$ & $3(2.65 \%)$ & $0(0 \%)$ \\
\hline OR(95\%CI) & $0.58(0.06-5.77)$ & & $0.97(0.93-1.01)$ \\
\hline$P$ & 1.00 & & 1.00 \\
\hline \multicolumn{4}{|l|}{ Recessive Model } \\
\hline Others & $53(98.15 \%)$ & $110(97.35 \%)$ & $19(100 \%)$ \\
\hline CC & $1(1.85 \%)$ & $3(2.65 \%)$ & $0(0 \%)$ \\
\hline OR(95\%CI) & $0.69(0.07-6.81)$ & & $0.97(0.94-1.00)$ \\
\hline$P$ & 1.00 & & 1.00 \\
\hline \multicolumn{4}{|l|}{ Dominant Model } \\
\hline TT & $48(88.89 \%)$ & $84(74.34 \%)$ & $19(100 \%)$ \\
\hline Others & $6(11.11 \%)$ & $29(25.66 \%)$ & $0(0 \%)$ \\
\hline OR(95\%CI) & $0.36(0.14-0.93)$ & & $0.74(0.67-0.83)$ \\
\hline$P$ & $0.031^{\star}$ & & $0.013^{*}$ \\
\hline \multicolumn{4}{|l|}{ Allelic frequencies } \\
\hline $\mathrm{T}$ & $101(93.52 \%)$ & $194(85.84 \%)$ & $38(100 \%)$ \\
\hline $\mathrm{C}$ & $7(6.48 \%)$ & $32(14.16 \%)$ & $0(0 \%)$ \\
\hline OR(95\%CI) & $0.42(0.18-0.99)$ & & $0.86(0.81-0.91)$ \\
\hline$P$ & $0.041^{*}$ & & $0.007^{*}$ \\
\hline
\end{tabular}

NPC (+): EBV-positive NPC; NPC(-): EBV-negative NPC; OR: odd ratio; 95\%CI: 95\% confidence interval; *: statistical significance. 
Table 5. Distribution of PPP1R15A polymorphisms in NPC (+) and NPC (-)

\begin{tabular}{|c|c|c|c|c|}
\hline $\begin{array}{l}\text { Genotype/allele } \\
\text { PPP1R15A(rs611251) }\end{array}$ & $\begin{array}{c}\mathrm{NPC}(+) \\
\mathrm{n}=\mathbf{5 4}(\%)\end{array}$ & $\begin{array}{c}\text { NPC }(-) \\
\mathrm{n}=19(\%)\end{array}$ & $\begin{array}{c}\text { OR } \\
(95 \% \mathrm{CI})\end{array}$ & $P$ \\
\hline \multicolumn{5}{|l|}{ Genotypic frequencies } \\
\hline $\mathrm{TT}$ & $48(88.89 \%)$ & $19(100 \%)$ & 1.00 & \\
\hline TC & $5(9.26 \%)$ & $0(0 \%)$ & $0.91(0.83-0.99)$ & 0.316 \\
\hline $\mathrm{CC}$ & $1(1.85 \%)$ & $0(0 \%)$ & $0.98(0.94-1.02)$ & 1.000 \\
\hline \multicolumn{5}{|l|}{ Recessive model } \\
\hline Others & $53(98.15 \%)$ & $19(100 \%)$ & 1.00 & \\
\hline $\mathrm{CC}$ & $1(1.85 \%)$ & $0(0 \%)$ & $0.98(0.95-1.02)$ & 1.000 \\
\hline \multicolumn{5}{|l|}{ Dominant model } \\
\hline TT & $48(88.89 \%)$ & $19(100 \%)$ & 1.00 & \\
\hline Others & $6(11.11 \%)$ & $0(0 \%)$ & $0.89(0.81-0.98)$ & 0.329 \\
\hline \multicolumn{5}{|l|}{ Allelic frequencies } \\
\hline $\mathrm{T}$ & $101(93.52 \%)$ & $38(100 \%)$ & 1.00 & \\
\hline $\mathrm{C}$ & $7(6.48 \%)$ & $0(0 \%)$ & $0.94(0.89-0.98)$ & 0.190 \\
\hline
\end{tabular}

NPC (+): EBV-positive NPC; NPC (-): EBV-negative NPC; OR: odd ratio; 95\%CI: 95\% confidence interval.

Table 6. Distribution of PPP1R15A polymorphisms in lymphoma and control

\begin{tabular}{|c|c|c|c|}
\hline $\begin{array}{l}\text { Genotype/allele } \\
\text { PPP1R15A(rs611251) }\end{array}$ & $\begin{array}{c}\text { Lymphoma (+) } \\
\text { n = } 93(\%)\end{array}$ & $\begin{array}{c}\text { Control } \\
\mathrm{n}=113(\%)\end{array}$ & $\begin{array}{c}\text { Lymphoma (-) } \\
n=53(\%)\end{array}$ \\
\hline \multicolumn{4}{|l|}{ Genotypic frequencies } \\
\hline TT & $80(86.02 \%)$ & $84(74.34 \%)$ & 47 (88.68\%) \\
\hline TC & $13(13.98 \%)$ & $26(23.01 \%)$ & $5(9.43 \%)$ \\
\hline OR(95\%CI) & $0.53(0.25-1.09)$ & & $0.34(0.12-0.96)$ \\
\hline$P$ & 0.082 & & $0.034^{*}$ \\
\hline $\mathrm{CC}$ & $0(0.00 \%)$ & $3(2.65 \%)$ & $1(1.89 \%)$ \\
\hline OR(95\%CI) & $0.97(0.93-1.01)$ & & $0.60(0.06-5.89)$ \\
\hline$P$ & 0.247 & & 1.000 \\
\hline \multicolumn{4}{|l|}{ Recessive model } \\
\hline Others & $100(100 \%)$ & $110(97.35 \%)$ & $52(98.11 \%)$ \\
\hline $\mathrm{CC}$ & $0(0.00 \%)$ & $3(2.65 \%)$ & $1(1.89 \%)$ \\
\hline OR(95\%CI) & $0.97(0.94-1.00)$ & & $0.71(0.07-6.94)$ \\
\hline$P$ & 0.249 & & 1.000 \\
\hline \multicolumn{4}{|l|}{ Dominant model } \\
\hline TT & $80(86.02 \%)$ & $84(74.33 \%)$ & $47(88.68 \%)$ \\
\hline Others & $13(13.98 \%)$ & $29(25.66 \%)$ & $6(11.32 \%)$ \\
\hline OR $(95 \% \mathrm{CI})$ & $0.47(0.23-0.97)$ & & $0.37(0.14-0.96)$ \\
\hline$P$ & $0.038^{\star}$ & & $0.035^{\star}$ \\
\hline \multicolumn{4}{|l|}{ Allelic frequencies } \\
\hline $\mathrm{T}$ & $173(93.01 \%)$ & $194(85.84 \%)$ & $99(93.40 \%)$ \\
\hline C & $13(6.99 \%)$ & $32(14.16 \%)$ & $7(6.60 \%)$ \\
\hline OR( $95 \% \mathrm{CI})$ & $0.46(0.23-0.90)$ & & $0.43(0.18-1.01)$ \\
\hline$P$ & $0.020^{*}$ & & $0.046^{*}$ \\
\hline
\end{tabular}

Lymphoma (+): EBV positive lymphoma; Lymphoma (-): EBV negative lymphoma; OR: odd ratio; 95\%CI: 95\% confidence interval; *: statistical significance.

and EBV-negative lymphomas than that in controls. Furthermore, the TC genotype and allele $\mathrm{C}$ showed a decreased risk of two groups. The genotypes and variants of PPP1R15A genes in the lymphomas are listed in Table 6. Moreover, no significant difference was found between EBV-positive lymphomas and EBV-negative lymphomas (Table 7). 
Table 7. Distribution of PPP1R15A polymorphisms in Lymphoma (+) and Lymphoma (-)

\begin{tabular}{|c|c|c|c|c|}
\hline $\begin{array}{l}\text { Genotype/allele } \\
\text { PPP1R15A(rs611251) }\end{array}$ & $\begin{array}{c}\text { Lymphoma }(+) \\
\text { n= } 93(\%)\end{array}$ & $\begin{array}{c}\text { Lymphoma (-) } \\
\text { n= } 53(\%)\end{array}$ & $\begin{array}{c}\text { OR } \\
(95 \% \mathrm{CI})\end{array}$ & $P$ \\
\hline \multicolumn{5}{|l|}{ Genotypic frequencies } \\
\hline TT & $80(86.02 \%)$ & $47(88.68 \%)$ & 1.00 & \\
\hline TC & $13(13.98 \%)$ & $5(9.43 \%)$ & $0.66(0.22-1.95)$ & 0.445 \\
\hline $\mathrm{CC}$ & $0(0.00 \%)$ & $1(1.89 \%)$ & $1.02(0.98-1.06)$ & 0.375 \\
\hline \multicolumn{5}{|l|}{ Recessive model } \\
\hline Others & $100(100 \%)$ & $52(98.11 \%)$ & 1.00 & \\
\hline $\mathrm{CC}$ & $0(0.00 \%)$ & $1(1.89 \%)$ & $1.02(0.98-1.06)$ & 0.346 \\
\hline \multicolumn{5}{|l|}{ Dominant model } \\
\hline TT & $80(86.02 \%)$ & $47(88.68 \%)$ & 1.00 & \\
\hline Others & $13(13.98 \%)$ & $6(11.32 \%)$ & $0.79(0.28-2.21)$ & 0.646 \\
\hline \multicolumn{5}{|l|}{ Allelic frequencies } \\
\hline $\mathrm{T}$ & $173(93.01 \%)$ & $99(93.40 \%)$ & 1.00 & \\
\hline $\mathrm{C}$ & $13(6.99 \%)$ & $7(6.60 \%)$ & $0.94(0.36-2.44)$ & 0.900 \\
\hline
\end{tabular}

Lymphoma (+): EBV-positive lymphoma; Lymphoma (-): EBV-negative lymphoma; OR: odd ratio; 95\%CI: 95\% confidence interval.

\section{Discussion}

In the present study, we first investigated PPP1R15A gene polymorphism (rs611251) in lymphomas, NPCs and GC specimens. The rs611251 is located at the genomic position of 48873829 on chromosome 19 . The mutation of this site is T-C nucleotide mutation, which leads to Val-Ala mutation. We found that the distribution of wild genotype TT and allele T showed a higher frequency in lymphomas, NPCs and GC samples, which may be a risk factor for these tumors. The allele $\mathrm{C}$ showed a decreased risk of lymphomas, NPCs and GC samples than that in controls. Consequently, the mutation of this site may be a protective factor for NPC, GC and lymphoma. However, little is known about the relationship between SNP (rs611251) with EBV-associated tumors.

It is well known that NPC is closely related to EBV infection. Expression of the oncogene LMP1 has been associated with NPC pathogenesis (Baichwal et al., 1988). In the present study, we found that the distribution of genotype TT and allele T showed a higher frequency both in EBV-positive NPCs and EBV-negative NPCs compared with the normal controls. The allele $\mathrm{C}$ also showed a decreased risk of EBV-positive NPCs and EBV-negative NPCs. It indicated that genotype TT and allele T may be a risk factor for NPCs.

GC is a heterogeneous disease that is largely influenced by $H$. pylori infection, environmental factors and genetic susceptibility. Epidemiological studies have shown that 95\% of the adults are infected with EBV infection, though half of the world's population suffers from $H$. pylori infection. However, only a small proportion of them progresses to chronic atrophic gastritis and ultimately GC (EBVaGC accounts for $1.3-20.1 \%$ in GC and 1-2\% H. pylori-infected cases develop GC) (Scholte et al., 2002; Akiba et al., 2008; Uozaki et al.,
2008; Lee et al., 2009). Furthermore, genetic factors may play key important roles in GC development.

Our results showed that the distribution of genotype TT and allele T of PPP1R15A (rs611251) had higher frequency in EBVnGC samples, while EBVaGCs does not reflect significant difference compared with normal controls. This difference may be related to the affection of EBV. However, the statistical analysis indicated that EBVaGCs and EBVnGCs had no significant difference with each other, but significant difference was found between GCs and controls. The genotype TT and allele T of PPP1R15A (rs611251) in GCs may be a risk factor for GCs.

In the present study we found that EBV-positive NPCs have significant difference compared with normal controls $(P<0.05)$, but the difference between EBVaGCs and normal controls was not significant $(P>0.5)$. NPC and GC were both EBV-associated epithelial carcinomas (Imai et al., 1994), however, they have different latency types of EBV. Different latency types correlate with specific EBV-associated malignancies (Babcock et al., 2000). It has been reported that oncogene LMP1 inhibits the differentiation of human epithelial cells. It is also related to cancer development, growth, invasion, metastasis, and the epithelial-mesenchymal transition (Dawson et al., 1990, Yoshizaki et al., 2002). Some authors have reported that LMP1 can be detected in $95.6 \%$ of NPC tissues and is associated with NPC pathogenesis, whereas the expression of LMP1 was not found in gastric cancer or in nonneoplastic gastric tissue (Baichwal et al., 1988; Tsang et al., 2003; Truong et al., 2009). Hence, the different expression of LMP1 maybe a way to explain our results and these findings require further study.

EBV is associated with various lymphoproliferative disorders, such as Burkitt's lymphoma, Hodgkin's lymphoma, T 
cell lymphoma, B cell lymphoma in immunodeficiency, and lymphoepithelioma-like carcinoma of the parotid gland (Young et al., 1992; Ambinder et al., 1994). Our study verified that genotype TT and allele T were also risk factors for lymphoma.

It was reported that overexpression of GADD34 enhanced the ability of EBNA3C to co-activate EBNA2, which could activate the LMP1 promoter. EBNA3C is essential to initiate $\mathrm{B}$-cell growth, as well as ongoing $\mathrm{B}$-cell transformation. Moreover, EBNA3C can interact with GADD34 that is upregulated in response to viral infection as well as ER-stress in both nuclear and cytoplasmic compartments and counteracts the unfolded protein response. In addition, the interaction also requires the domination of the HSV-1 ICP $\gamma 34.5$, which shares homology with GADD34 in the PP1-binding domain (He et al., 1997; Garrido et al., 2009). However, no significant difference was found between three kinds of EBV-associated tumors and corresponding EBV-negative tumors. EBV infection may not play a vital role in the SNP (rs611251) of PPP1R15A. The exact mechanism is not yet clear. Further in-depth study and analysis will be necessary under rather more naturalistic conditions to confirm the relationship between PPP1R15A gene polymorphisms and EBV-associated tumors. Our results are the first to identify that PPP1R15A gene SNP (rs611251) has association with multiple tumor types, which may provide some new clues to the detection and treatment of tumors.

\section{Conclusions}

Our present results indicate that the PPP1R15A rs611251 polymorphism was significantly related to three kinds of tumors (NPC, GC and lymphoma). The genotype TT and allele T could be risk factors for NPC, GC and lymphoma. Nevertheless, EBV has no obvious effect on PPP1R15A rs611251 polymorphism.

Acknowledgements. This work was supported by National Natural Science Foundation of China (NSFC 81571995), and Natural Science Foundation of Shandong Province (ZR2015HM069).

\section{References}

Akiba S, Koriyama C, Herrera-Goepfert R, Eizuru Y (2008): EpsteinBarr virus associated gastric carcinoma: Epidemiological and clinicopathological features. Cancer Sci. 99, 195-201. https://doi.org/10.1111/j.1349-7006.2007.00674.x

Ambinder RF, Mann RB (1994): Detection and characterization of Epstein-Barr virus in clinical specimens. Am. J. Pathol. $145,239-252$.

Baichwal VR, Sugden B (1988): Transformation of Balb 3T3 cells by the BNLF-1 gene of Epstein-Barr virus. Oncogene 2, 461-2467.
Babcock GJ, Hochberg D, Thorley-Lawson AD (2000): The expression pattern of Epstein-Barr virus latent genes in vivo is dependent upon the differentiation stage of the infected B cell. Immunity 13, 497-506. https://doi.org/10.1016/ $\underline{\text { S1074-7613(00)00049-2 }}$

Chang PY, Huang Y, Hung TY, Chong KY, Chang YS, Chao CC, Chow KN (2000): Spontaneous metastases in immunocompetent mice harboring a primary tumor driven by oncogene latent membrane protein 1 from Epstein-Barr virus. Biomed. J. 39, 261-271. https://doi.org/10.1016/j. bj.2015.12.003

Dawson CW, Rickinson AB, Young LS (1990): EBV latent membrane protein inhibits human epithelial cell differentiation. Nature 344, 777-780. https://doi.org/10.1038/344777a0

Garrido JL, Maruo S, Takada K, Rosendorff A (2009): EBNA3C interacts with Gadd 34 and counteracts the unfolded protein response. Virol. J. 6, 231. https://doi.org/10.1186/1743$\underline{422 \mathrm{X}-6-231}$

He B, Gross M, Roizman B (1997): The gamma(1)34.5 protein of herpes simplex virus 1 complexes with protein phosphatase 1alpha to dephosphorylate the alpha subunit of the eukaryotic translation initiation factor 2 and preclude the shutoff of protein synthesis by double-stranded RNAactivated protein kinase. Proc. Natl. Acad. Sci. USA 94, 843-848. https://doi.org/10.1073/pnas.94.3.843

Hollander MC, Sheikh MS, Yu K, Zhan Q, Iqlesias M, Woodworth C, Fornace AJ Jr (2001): Activation of Gadd34 by diverse apoptotic signals and suppression of its growth inhibitory effects by apoptotic inhibitors. Int. J. Cancer 96, 22-31. https://doi.org/10.1002/1097-0215(20010220)96:1<22::AID-IJC3>3.0.CO;2-K

Imai S, Koizumi S, Sugiura M, Tokunaqa M, Uemura Y, Yamamoto N, Tanaka S, Sato E, Liu L, Ito S, Nishio N, Sun Y, Chen N, Tanaka Y, Isobe K (2015): GADD34 facilitates cell death resulting from proteasome inhibition. Anticancer Res. 35, 5317-5324.

Kuang X, Sun L, Liu S, Zhao D, Liu S, Luo B (2016): Association of single nucleotide polymorphism rs2065955 of the filaggrin gene with susceptibility to Epstein-Barr virus-associated gastric carcinoma and EBV-negative gastric carcinoma. Virol. Sin. 31, 306-313. https://doi. org/10.1007/s12250-016-3721-9

Lee JH, Kim SH, Han SH, An JS, Lee ES, Kim YS (2009): Clinicopathological and molecular characteristics of EpsteinBarr virus-associated gastric carcinoma: A meta-analysis. J. Gastroenterol. Hepatol. 24, 354-365. https://doi. org/10.1111/j.1440-1746.2009.05775.x

Liu L, Ito S, Nishio N, Sun Y, Tanaka Y, Isobe K (2016): GADD34 promotes tumor growth by inducing myeloid-derived suppressor. Anticancer Res. 36, 4623-4628. https://doi. org/10.21873/anticanres.11012

Pipan V, Zorc M, Kunej T (2015): MicroRNA polymorphisms in cancer: A literature analysis. Cancers (Basel) 7, 18061814. https://doi.org/10.3390/cancers7030863

Roh SA, Park IJ, Yoon YS, Kwon YH, Chung JH, Kim TW, Cho DH, Lim BH, Kim SK, Kim SY, Kim YS, Kim JC (2016): Feasibility of novel PPP1R15A and proposed ANXA11 single nucleotide polymorphisms as predictive markers 
for bevacizumab regimen in metastatic colorectal cancer. Cancer Res. Clin. Oncol. 142, 1705-1714. https://doi. org/10.1007/s00432-016-2177-5

Scholte GH, Van Doorn LJ, Cats A, Bloemena E, Lindeman J, Quint WG, Meuwissen SG, Kuipers EJ (2002): Genotyping of Helicobacter pylori in paraffin-embedded gastric biopsy specimens: Relation to histological parameters and effects on therapy. Am. J. Gastroenterol. 97, 1687-1695. https:// doi.org/10.1111/j.1572-0241.2002.05775.x

Thompson MP, Kurzrock R (2004): Epstein-Barr virus and cancer. Clin. Cancer Res. 10, 803-821. https://doi. org/10.1158/1078-0432.CCR-0670-3

Truong CD, Feng W, Li W, Khoury T, Li Q, Alrawi S, Yu Y, Xie K, Yao J, Tan D (2009): Characteristics of Epstein-Barr virusassociated gastric cancer: a study of 235 cases at a comprehensive cancer center in U.S.A. J. Exp. Clin. Cancer Res. 28, 14. https://doi.org/10.1186/1756-9966-28-14

Tokunaga M, Land CE, Uemura Y, Tokudome T, Tanaka S, Sato E (1993): Epstein-Barr virus in gastric carcinoma, Am. J. Pathol. 143, 1250-1254.

Tanaka Y, Ito S, Oshino R, Chen N, Nishio N, Isobe K (2015): Effects of growth arrest and DNA damage-inducible protein 34 (GADD34) on inflammation-induced colon cancer in mice. Br. J. Cancer 113, 669-679. https://doi.org/10.1038/ bjc. 2015.263
Uozaki H, Fukayama M (2008): Epstein-Barr virus and gastric carcinoma-viral carcinogenesis through epigenetic mechanisms. Int. J. Clin. Exp. Pathol. 1, 198-216.

Wallance DM (1987): Large- and small-scale phenol extractions. Methods Enzymol. 152, 33-41. https://doi. org/10.1016/0076-6879(87)52007-9

Wu XJ, Mi YY, Yang H, Hu AK, Li C, Li XD, Zhang QG (2013): Association of the hsa-mir-499 (rs3746444) polymorphisms with gastric cancer risk in the Chinese population. Onkologie 36, 573-576. https://doi. org $/ 10.1159 / 000355518$

Xu Q, Liu JW, Yuan Y (2015): Comprehensive assessment of the association between miRNA polymorphisms and gastric cancer risk. Mutat. Res. Rev. Mutat. Res. 763, 148-160. https://doi.org/10.1016/j.mrrev.2014.09.004

Young SK, Shao Y, Bidwell JP, Wek RC (2016): Nuclear matrix protein 4 is a novel regulator of ribosome biogenesis and controls the unfolded protein response via repression of Gadd34 expression. J. Biol. Chem. 291, 13780-13788. https://doi.org/10.1074/jbc.M116.729830

Yoshizaki T (2002): Promotion of metastasis in nasopharyngeal carcinoma by Epstein-Barr virus latent membrane protein-1. Histol. Histopathol. 17, 845-850.

Young LS, Rowe M (1992): Epstein-Barr virus, lymphomas and Hodgikin's disease. Semin. Cancer Biol. 3, 273-284 